\title{
AGROINDÚSTRIAS FAMILIARES RURAIS: UM ESTUDO DOS EMPREENDIMENTOS DO MUNICÍPIO DE CONSTANTINA-RS
}

\author{
RURAL FAMILY AGROINDUSTRIES: A STUDY OF COMPANIES IN THE \\ MUNICIPALITY OF CONSTANTINA-RS \\ AGROINDUSTRIAS RURALES FAMILIARES: UN ESTUDIO CON EMPRESAS DEL \\ MUNICIPIO DE CONSTANTINA-RS
}

\author{
Caroline Conteratto ${ }^{1}$ \\ https://orcid.org/0000-0002-3838-2898 \\ Alessandra Matte ${ }^{2}$ \\ ttps://orcid.org/0000-0002-0502-6643 \\ Rosani Marisa Spanevello ${ }^{3}$ \\ https://orcid.org/0000-0002-4278-6895 \\ Tanice Andreatta ${ }^{4}$ \\ https://orcid.org/0000-0002-1427-2248
}

Submissão: 25/05/2020 / Aceito: 06/10/2020 / Publicado: 30/06/2021.

\begin{abstract}
Resumo
O objetivo desta pesquisa é identificar as percepções de agricultores acerca das atividades envolvendo agroindústrias rurais familiares do município de Constantina, situado na mesorregião Noroeste do estado do Rio Grande do Sul. Por meio do estudo de múltiplos casos, analisaram-se 21 empreendimentos. Os empreendimentos são de pequeno porte, a mão de obra é familiar, e a inserção nos mercados ocorre majoritariamente por meio de feiras livres, dos supermercados e da venda direta em domicílios. Como fatores dinamizadores destes mercados, os entrevistados elencaram a qualidade dos produtos, as relações de confiança e a possibilidade do conhecimento da origem e do processo de produção.
\end{abstract}

Palavras-chave: Agroindústria familiar rural, segurança alimentar, produção, consumo.

\footnotetext{
Abstract

The objective of this research is to identify the perceptions of farmers about activities involving rural family agroindustry's in the municipality of Constantina, located in the northwestern mesoregion of the state of Rio Grande do Sul. Through the study of multiple cases, 21 projects were analyzed. The ventures are small, the workforce is familiar and the insertion in the markets takes place mostly through open fairs, supermarkets and direct sales at home. As driving factors of these markets, the

${ }^{1}$ Economista, Mestra em Agronegócios (UFRGS). Atualmente é Doutoranda em Agronegócios na Universidade Federal da Grande Dourados (UFGD). E-mail:carolineconteratto@ hotmail.com

${ }^{2}$ Zootecnista, Mestra e Doutora em Desenvolvimento Rural. Atualmente é Professora Adjunta na Universidade Federal Tecnológica do Paraná (UFTP), Campus Santa Helena. E-mail: alessandramatte@ yahoo.com.br

${ }^{3}$ Agrônoma, Mestra em Extensão Rural e Doutora em Desenvolvimento Rural. Atualmente é Professora Adjunta na Universidade Federal de Santa Maria (UFSM). E-mail: rspanevello@yahoo.com.br

${ }^{4}$ Economista, Mestra e Doutora em Desenvolvimento Rural. Atualmente é Professora Adjunta na Universidade Federal de Santa Maria (UFSM). E-mail: tanice.andreatta@ufsm.br
} 
interviewees listed the quality of the products, the relationships of trust and the possibility of knowing the origin and the production process.

Keywords: Family rural agribusiness, food security, production, consumption.

\section{Resumen}

El objetivo de esta investigación es identificar las percepciones de los agricultores sobre las actividades que involucran a las agroindustrias familiares rurales en el municipio de Constantina, ubicado en la mesorregión noroccidental del estado de Rio Grande do Sul. Mediante el estudio de múltiples casos, se analizaron 21 proyectos. Los emprendimientos son pequeños, la mano de obra es familiar y la inserción en los mercados se realiza principalmente a través de mercados abiertos, supermercados y venta directa a domicilio. Como factores impulsores de estos mercados, los entrevistados enumeraron la calidad de los productos, las relaciones de confianza y la posibilidad de conocer el origen y el proceso de producción.

Palabras clave: agroindustria familiar rural, seguridad alimentaria, producción, consumo.

\section{INTRODUÇÃo}

No momento em que decide processar ou regularizar sua produção rural para agregar valor ou mesmo evitar a necessidade de intermediários na venda da produção, o agricultor deve estar preparado para adequar-se às exigências sanitárias e à complexidade dos mercados agroalimentares, e dispor de recursos para investir em estruturas para o processamento dos seus produtos. No que concerne ao primeiro aspecto, pesquisas têm apontado que, diante da inadequação das normas sanitárias à realidade dos produtores rurais, estes têm optado por manter a produção rural na informalidade, restringindo a legalização das agroindústrias rurais familiares (WAQUIL, 2013; FERNANDES; ENGEL, 2016; GAZOLLA, 2017; CRUZ, 2020).

Por outro lado, aqueles que superam esse desafio deparam-se com a complexidade dos mercados e do acesso aos espaços de comercialização, especialmente diante do predomínio do pequeno número de multinacionais que dominam os mercados alimentares (CRUZ; MENASCHE, 2014; CRUZ, MATTE, SCHNEIDER, 2016; WESZ JUNIOR, 2017; CRUZ, 2020). De maneira geral, em anos recentes, o Estado brasileiro tem fomentado apoio na regularização dessa produção, por meio de políticas públicas específicas para esse cenário, buscando facilitar a regularização dessa produção e fomentar práticas direcionadas a garantir a segurança alimentar por meio do incentivo e da valorização dessa produção (FERNANDES; ENGEL, 2016; RAUPP; GAZOLLA, 2017; WESZ JUNIOR, 2017). Em particular, a formalização permite a ampliação do escopo de canais de comercialização, mas, por outro lado, pode incorrer em perda da artesanalidade e de atributos organolépticos singulares (FERNANDES; ENGEL, 2016; VIANA; TRICHES, CRUZ; 2019). 
Por fim, o investimento em estrutura física para o processamento pode representar importante avanço para o reconhecimento da qualidade sanitária de produtos da agricultura familiar, conforme apontado em estudo realizado por Cruz (2007) na Associação dos Agricultores Familiares das Encostas da Serra Geral (AGRECO), sediada em Santa Rosa de Lima, Santa Catarina. A autora destaca que a agroindustrialização tende a contribuir, de forma efetiva, para a geração de renda e para melhorias na qualidade de vida no meio rural, levando em conta as motivações dos agricultores, as especificidades do sistema produtivo e as características da agricultura familiar (CRUZ, 2007).

Em anos recentes, o incentivo às agroindústrias rurais familiares tem sido não apenas provocado pelas mudanças com relação aos hábitos de consumo e do protagonismo dos consumidores, mas também fomentado por meio de políticas públicas direcionadas especialmente à regularização e ao fomento de canais de comercialização. De acordo com o Censo Agropecuário de 2017, atualmente são registrados 852.639 estabelecimentos agropecuários com agroindústria rural, montante equivalente a $16,8 \%$ dos estabelecimentos rurais no Brasil que beneficiaram e/ou transformaram algum tipo de matéria-prima (IBGE, 2019). Ao refinar esses dados, é possível identificar que, do total de agroindústrias rurais no Brasil, 720.644 (84,5\%) estabelecimentos que possuem agroindústria são de agricultura familiar.

As principais atividades desenvolvidas nas agroindústrias rurais brasileiras, de acordo com o IBGE (2019), são produção de farinha de mandioca (41,7\% das agroindústrias, equivalente a 355.207 estabelecimentos rurais), de queijo e requeijão (20,5\% das agroindústrias, equivalente a 175.198 estabelecimentos rurais), de carne suína (17,3\% das agroindústrias, equivalente a 147.543 estabelecimentos rurais), de carne bovina (14,3\% das agroindústrias, equivalente a 121.695 estabelecimentos rurais) e de carne de outros animais (14,1\% das agroindústrias, equivalente a 120.561 estabelecimentos rurais). Contudo, essa sequência é modificada quando analisada a quantidade produzida, tendo como maior produção a de carvão vegetal $\left(1^{\circ}\right)$, seguida das produções de farinha de mandioca $\left(2^{\circ}\right)$, algodão em pluma $\left(3^{\circ}\right)$, queijo e requeijão (4) e caroço de algodão $\left(5^{\circ}\right)$. Outra ordenação é visualizada quando analisado o valor da produção. Em ordem decrescente estão: algodão em pluma $\left(1^{\circ}\right)$, queijo e requeijão $\left(2^{\circ}\right)$, carvão vegetal $\left(3^{\circ}\right)$ e a farinha de mandioca $\left(4^{\circ}\right)$.

Em particular, no âmbito do consumo, com as mudanças no estilo de vida e principalmente nos hábitos alimentares, os consumidores têm se interessado cada vez mais pela procedência, informações nutricionais e sustentabilidade dos alimentos (SCARABELOT; SCHNEIDER, 2012; CRUZ, MATTE, SCHNEIDER, 2016; CARON et al., 2020; CONTERATO; VASCONCELLOS, 2020). Tais mudanças têm ocasionado uma valorização da produção local. 
Atualmente a produção de alimentos no mundo, inclusive a agroindustrialização, tem se mostrado uma alternativa de diversificação econômica para quem vive no campo, além de ser uma atividade de subsistência (PLOEG, 2016; GARCIA-PARPET, 2016, CRUZ, 2020). A este respeito, Ploeg $(2011$; 2016) afirma que as falhas de mercado, assim como a emergência de desafios relativos ao desenvolvimento rural, muitas vezes devem ser solucionadas de maneira local, ainda que os problemas sejam globais.

As demandas de diferentes modos de produção e consumo estão, em larga medida, associadas a alterações relacionadas a questões de saúde e bem-estar, aspectos econômicos e sociais, e ainda, à sustentabilidade em um sistema econômico. Nesse sentido, Wilkinson (2008), direcionando olhar para a realidade brasileira, menciona que os circuitos curtos de comercialização contribuem para a valorização do conhecimento local e a valorização da agricultura orgânica, por exemplo, como um modo de estabelecer uma relação justa e próxima com os consumidores. Mais recentemente, o autor destaca que há uma complexidade entre mercados e sociedade, assumindo que se tratam de práticas sociais por excelência, na medida em que não sujeitas a uma única lógica dominante (WILKINSON, 2016).

Isso posto, a proximidade com o alimento e o conhecimento acerca do modo de sua produção e do seu processamento permite que o consumidor valorize a agroindústria local como fonte de acesso a alimentos. Esses canais curtos de comercialização, nesse caso, as agroindústrias familiares rurais, oferecem aos consumidores não somente alimento, mas uma relação de reciprocidade e confiança. Destarte, estes mercados com espaço característico próximo possuem interdependência social que desenvolve uma relação direta entre os produtores e os consumidores (AGNE; WAQUIL, 2011; GRANOVETTER, 2007; WAQUIL, 2013; FORNAZIER; BELIK, 2013).

A pluralidade quanto às dinâmicas que caracterizam as agroindústrias no espaço rural ainda desafia os pesquisadores a compreender como se desenvolvem os fatores dinamizadores deste setor. Nesse sentido, ainda existem lacunas quanto ao entendimento do perfil e das percepções desses agentes, ou seja, os agricultores que produzem e beneficiam alimentos na propriedade rural.

Mior (2005) destaca que o fato de a agroindústria familiar rural desempenhar um modo particular de produção, processamento ou transformação de sua produção agrícola e pecuária, constitui o valor de troca por meio da comercialização. Da mesma forma, Gazolla e Pelegrini (2008) entendem que na agricultura familiar existe um processo de reprodução social em que, especialmente os empreendedores agroindustriais, que são agentes responsáveis pelo desenvolvimento rural, uma vez que fazem a gestão e o uso do trabalho do núcleo familiar, definem múltiplas estratégias. 
No Rio Grande do Sul, em particular na região Noroeste do estado, esse processo passa a receber destaque mediante a emergência da produção de alimentos para o autoconsumo por parte dos imigrantes europeus que colonizaram a região. A tradição da produção de alimentos, apesar do êxodo rural que se mostrou significativo nos últimos anos, estreitou de maneira espacial o campo e a cidade, criando uma maior autonomia para os agricultores (BOURSCHEID et al., 2016; CRUZ, 2020). Na mesorregião Noroeste do Rio Grande do Sul, há predomínio de estabelecimentos rurais classificados como de agricultura familiar, representando 84,9\% (50.681) do total de propriedades rurais, sendo que $65,1 \%$ possuem entre 0 e 20 hectares. Nesse cenário, historicamente há registro da transformação da produção ou parte da produção pelos próprios agricultores, bem como a geração de produtos in natura, atividades e processamentos que têm se mostrado um espaço fértil para a legalização de agroindústrias rurais.

Diante desse contexto, o objetivo desta pesquisa é identificar as percepções de agricultores acerca das atividades envolvendo agroindústrias rurais familiares do município de Constantina, situado na mesorregião Noroeste do estado do Rio Grande do Sul. Para tanto, o artigo está dividido em duas seções, além desta introdução e das considerações finais. Na primeira seção são apresentados os procedimentos de pesquisa, e na segunda, a sistematização e a análise dos resultados.

\section{PROCEDIMENTOS DE PESQUISA}

Para a realização deste estudo foram considerados todos os estabelecimentos rurais que possuíam uma agroindústria familiar rural - beneficiaram e/ou transformaram produtos -, localizados no município de Constantina-RS, no ano de 2017 (Figura 1). Esse município, situado na mesorregião Noroeste do estado do Rio Grande do Sul, abrange uma área de 203 Km² (IBGE, 2017), e, em larga medida, é representativo, no estado do Rio Grande do Sul, no que se refere à temática estudada.

O Censo Demográfico de 2010 demonstrou que aproximadamente 34\% dos habitantes residem na área rural, e 66\% na área urbana (IBGE, 2010). A agropecuária tem um papel importante na economia do município e tem como destaque a produção de grãos, leite e suínos. De acordo com o Censo Agropecuário de 2017, o município possui 824 propriedades rurais, das quais 92\% são de agricultura familiar. $72 \%$ do total das propriedades estão na esfera de 5 e até 50 hectares (IBGE, 2017). De acordo com Hennig (2010), aproximadamente $75 \%$ dos estabelecimentos agropecuários do município apresentam menos de 20 hectares, e 97\%, menos de 50 hectares. 
Figura 1 - Mapa da localização do município de Constantina, no Noroeste do estado do Rio Grande do Sul.

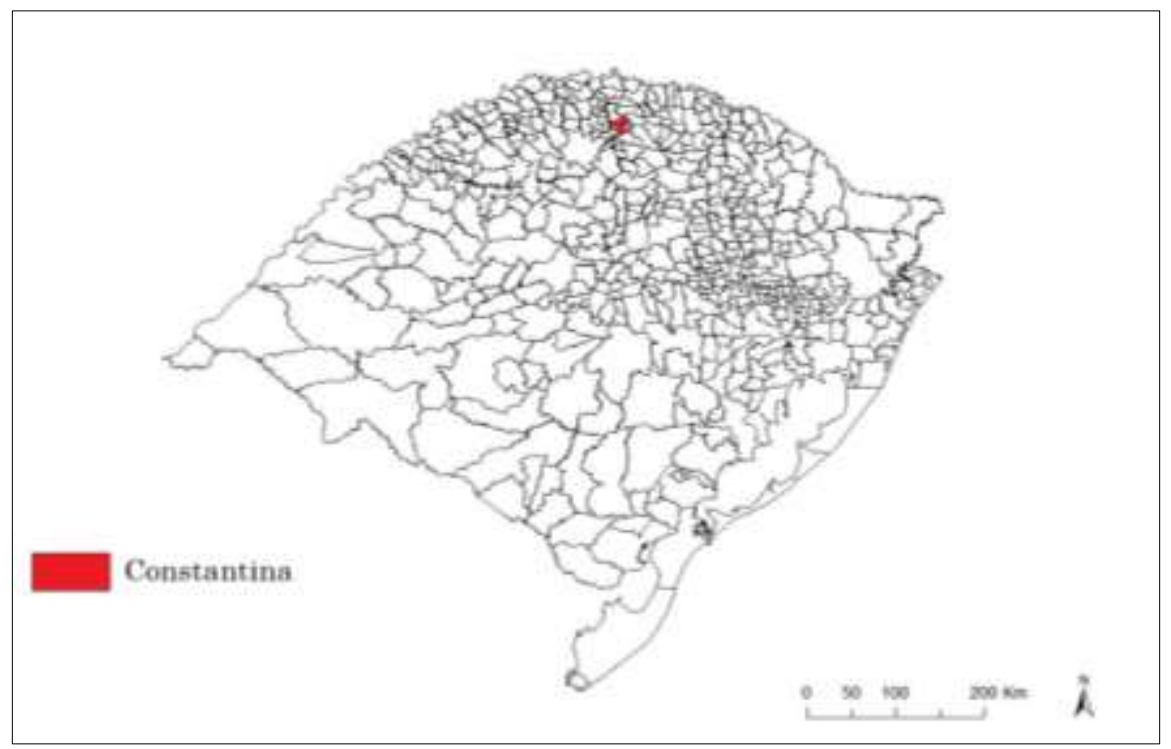

Fonte: Elaborado pelas autoras a partir de base cartográfica do IBGE.

O surgimento dos empreendimentos de pequeno porte teve sua origem motivada pela crise da produção do binômio trigo e soja, implementado no município na década de 1970. Conforme Hennig (2010), muitos agricultores com baixo grau de capitalização e com áreas de difícil mecanização não conseguiam produzir para manter um nível mínimo de reprodução da família. Diante destas dificuldades, instituições locais de desenvolvimento rural motivaram, a partir de 1990, uma proposta de diversificação da matriz produtiva do município, a qual incluía produzir novos sistemas ou melhorar os já existentes, tais como: atividade leiteira, suinocultura integrada com a indústria, fruticultura (uva e laranja) e produção de fumo.

Ainda nesse sentido, com vistas a aumentar a diversificação produtiva e agregar valor, no final de década de 1990, segundo Hennig (2010), foi proposto um programa específico de agroindustrialização familiar de pequeno porte com o apoio das instituições locais, que se encarregaram de criar as condições de financiamento, comercialização e assistência técnica aos agricultores. Esta iniciativa foi importante para que muitas propriedades e famílias passassem a direcionar os esforços de geração de renda em produtos diferenciados, tais como embutidos, panificados, hortifrugranjeiros, entre outros, e não apenas na produção de grãos.

A escolha desse município para a realização deste estudo se deu pela expressividade de habitantes que ainda residem no meio rural, bem como pelo percentual de estabelecimentos de base 
familiar, e, sobretudo, pelo fato de o município ser referência em termos de transformação e comercialização de produtos oriundos da agricultura familiar.

Nesse sentido, foram entrevistados 21 proprietários(as) e/ou responsáveis por estabelecimentos que desenvolviam atividades relacionadas à comercialização de produtos in natura, ou ainda faziam industrialização de produtos agropecuários, totalizando as agroindústrias rurais legalizadas do município. É importante destacar que estes empreendimentos se referem ao universo dos que produzem alimentos processados em agroindústrias transformadoras de produtos agroalimentares e in natura, que, na sua maioria, circulam na economia do município e arredores. Dos 21 empreendimentos, 15 são configurados a partir da transformação de produtos agropecuários. Dentre estes, três produzem derivados de cana-de-açúcar; quatro produzem derivados de carne suína; três agroindústrias produzem derivados de leite; quatro agroindústrias produzem pães, biscoitos e massas; e cinco estabelecimentos produzem hortifrutigranjeiros.

Para facilitar a descrição e análise dos dados da pesquisa de forma geral, mas também as especificidades de cada agroindústria, foi criada uma nomenclatura para definir os empreendimentos. As agroindústrias de processamento de produção animal (embutidos de carne suína, derivados de leite) e vegetal (derivados de cana-de-açúcar) são representadas pelas abreviaturas A1, A2, A3, A4, A5, A6, A7, A8, A9, A10 e A11. Para representar as agroindústrias processadoras de pães, biscoitos e massas, utilizaram-se P12, P13, P14 e P15. Os estabelecimentos produtores de hortifrutigranjeiros foram representados pelas abreviações H16, H17, H18, H19, H20, $\mathrm{H} 21$.

As entrevistas ocorreram no período que compreendeu os meses de janeiro e fevereiro de 2017, por meio de visitas in loco nos empreendimentos considerados na pesquisa. A identificação e localização dos produtores e/ou agroindústrias foram obtidas junto à COOPERAC (Cooperativa de Produção de Alimento dos Agricultores Familiares de Constantina-RS), e ao SINTRAF (Sindicato dos Trabalhadores e Trabalhadoras na Agricultura Familiar de Constantina-RS). Estas duas organizações forneceram as informações sobre a população dos estabelecimentos que estavam atuando na produção e comercialização de alimentos in natura e/ou agroindustrializados no município.

A construção do roteiro de pesquisa baseou-se nos estudos de Pelegrini e Gazolla (2007) e Cassol (2013), desenvolvidos por estes autores para analisar a agricultura familiar, assim como a produção e transformação de alimentos. Para a realização das entrevistas utilizou-se um roteiro de entrevista que continha questões predominantemente fechadas. As questões fechadas, em sua grande 
maioria, foram formuladas por meio da escala de Likert, considerando que (1) discordo totalmente, (2) discordo parcialmente, (3) nem concordo e nem discordo, (4) concordo parcialmente e (5) concordo totalmente. As questões abertas foram realizadas com o intuito de captar a percepção dos entrevistados acerca de questões-chave sobre o funcionamento dos estabelecimentos e também para contribuir na interpretação de questões de natureza quantitativa.

\section{RESULTADOS E DISCUSSÕES}

Os resultados são apresentados em duas seções. Na primeira é realizada a caraterização da família e dos empreendimentos familiares, assim como os meios de produção utilizados para elaboração dos produtos. $\mathrm{Na}$ segunda seção, são analisadas as percepções dos entrevistados referentes às questões de características dos produtos e da comercialização.

\section{Caracterização das famílias, empreendimentos e da produção}

Considerando os entrevistados e suas respectivas famílias, o número total é de 79 indivíduos, dos quais 39 são mulheres, e 40, homens, sendo que $70 \%$ dos entrevistados possuem acima de 40 anos. Em sua maioria, são sócios-proprietários dos empreendimentos, que, em larga medida, herdaram a tradição de transformação e beneficiamento de alimentos de seus antepassados. Nota-se a presença do conhecimento tácito, adquirido na prática. A maioria dos entrevistados não possui curso profissionalizante e de especialização, e apresentam um nível de escolaridade baixo - mais da metade $(58 \%)$ das pessoas ocupadas possuem ensino fundamental incompleto. De acordo com a visão dos entrevistados, isso ocorre porque, quando estavam na idade de estudar, os pais tinham a necessidade de mão de obra na propriedade, o que os impedia de frequentar a escola por mais tempo.

De modo geral os empreendimentos são de pequeno porte (Tabela 1), uma vez que 47,62\% possuem até 10 hectares. Além da transformação de produtos agroalimentares, somam-se outras atividades produtivas, cujos produtos são comercializados in natura, ou ainda, são utilizados como insumos para abastecer as agroindústrias.

Tabela 1 - Tamanho da área dos empreendimentos (em hectares)

\begin{tabular}{ccc}
\hline Tamanho da área (em ha) & $\mathrm{N}^{\circ}$ de empreendimentos & \% de empreendimentos \\
\hline Até 5 & 6 & 28,57 \\
Entre 5,1 e 10 & 4 & 19,05 \\
Entre 10,1 e 20 & 2 & 9,52 \\
Entre 20,1 e 30 & 4 & 19,05 \\
Entre 30,1 e 40 & 3 & 14,29
\end{tabular}

DOI: http://dx.doi.org/10.22295/grifos.v30i53.5510| Edição Vol. 30, Núm. 53, 2021. 
Entre 40,1 e 50

Total
2

21
9,52

100

Fonte: Dados da pesquisa de campo.

A produção está distribuída entre a agroindustrialização de embutidos de carne suína (05 empreendimentos), derivados de leite (03 empreendimentos), derivados de cana-de-açúcar (03 empreendimentos), panificados (04 empreendimentos) e hortifrutigranjeiros (06 empreendimentos). Dos 21 empreendimentos, 15 deles atuam de maneira formal, tendo algum tipo de selo, quais sejam: o SIM (Sistema de Inspeção Municipal), ou ainda selos que são conferidos por instituições (Quadro 2).

Quadro 2 - Configuração dos empreendimentos

\begin{tabular}{|c|c|c|c|}
\hline Agroindústria & Ano de constituição & Tipo de produtos comercializados & Situação legal \\
\hline A1 & 2007 & Embutidos de carne suína. & Formal \\
\hline A2 & 1995 & Embutidos de carne suína. & Informal \\
\hline $\mathrm{A} 3$ & 2001 & Embutidos de carne suína. & Formal \\
\hline A4 & 2006 & Embutidos de carne suína. & Informal \\
\hline A5 & 2002 & Embutidos de carne suína. & Formal \\
\hline A6 & 2012 & Derivados de leite. & Formal \\
\hline A7 & 2005 & Derivados de leite. & Formal \\
\hline A8 & 2002 & Derivados de leite. & Formal \\
\hline A9 & 1999 & Derivados de cana-de-açúcar. & Formal \\
\hline A10 & 1997 & Derivados de cana-de-açúcar. & Formal \\
\hline A11 & 2002 & Derivados de cana-de-açúcar. & Formal \\
\hline $\mathrm{P} 12$ & 2014 & Massas, pães, biscoitos. & Formal \\
\hline P13 & 2002 & Massas, pães, biscoitos. & Formal \\
\hline $\mathrm{P} 14$ & 2014 & Massas, pães, biscoitos. & Formal \\
\hline P15 & 2011 & Massas, pães, biscoitos. & Formal \\
\hline H16 & 2016 & Alface, rúcula, tomate e pimentão. & Informal \\
\hline $\mathrm{H} 17$ & 2014 & Alface, rúcula, tomate, morango, abóbora e repolho & Informal \\
\hline H18 & 2014 & Alface, rúcula e tomate. & Informal \\
\hline H19 & 2011 & Alface, tomate e hortaliças. & Informal \\
\hline $\mathrm{H} 20$ & 2015 & Pepinos & Informal \\
\hline $\mathrm{H} 21$ & 2016 & Alface, tomate, couve-flor e chicória. & Informal \\
\hline
\end{tabular}

Fonte: Dados da pesquisa.

*Serviço de Inspeção Municipal

Nos empreendimentos que produzem alimentos de origem animal e vegetal, a forma de produção predominante é a convencional, como, por exemplo, os alimentos geneticamente modificados e os que fazem uso de agroquímicos. Neste caso, somente três empreendimentos produzem de forma orgânica. Os entrevistados apontam que a forma convencional de produção 
exige menos mão de obra e tem menor complexidade quanto à adequação exigida para o enquadramento na classificação de produção orgânica.

Em termos de formalização dos empreendimentos, oito deles atuam de maneira informal. No entanto, na visão dos proprietários de empreendimentos informais, mesmo cientes do risco, há preferência por operar desta forma devido à dificuldade de se adaptar às exigências dos órgãos responsáveis, principalmente da parte burocrática.

Dos 21 estabelecimentos de produção agroalimentar estudados, somente três deles utilizam esta atividade como fonte de renda principal. Os demais diversificam a atividades em suas unidades produtivas de acordo com a extensão de terra e a mão de obra disponível (Tabela 2). Nesta perspectiva, Ellis (2000) menciona que a diversificação nos estabelecimentos é uma estratégia de sobrevivência. Assim, a agroindustrialização, além de agregar modelos de trabalho e de reprodução social, é uma forma de enfrentar as dificuldades e principalmente de gerar renda.

Tabela 2 - Atividades executadas nos empreendimentos além da agroindustrialização e de hortifrutigranjeiros

\begin{tabular}{cc}
\hline Atividade (s) & Valor Absoluto \\
\hline Produção de grãos e produção de leite & 8 \\
Produção de grãos & 6 \\
Produção de leite & 1 \\
Produção de grãos, produção de leite e turismo rural & 1 \\
Ovinocultura & 1 \\
Produção de grãos e suinocultura & 1 \\
Não possui atividades agrícolas & 3 \\
Total & 21 \\
\hline
\end{tabular}

Fonte: Dados da pesquisa de campo.

Assim, a maioria dos produtores afirma que utiliza a produção agroindustrializada, e a produção s hortifrutigranjeira como uma atividade complementar. Menciona ainda que a formação das agroindústrias se deu principalmente pela necessidade de complementação da renda. Predominam nestas unidades, juntamente com a agroindustrialização, a produção de grãos, bem como atividades de produção leiteira, suinocultura, ovinocultura e turismo rural (Tabela 2).

Tabela 3 - Razões da origem da implantação da agroindustrialização e produção de hortifrutigranjeiros nos empreendimentos

\begin{tabular}{c|c}
\hline Razões de origem dos empreendimentos & $\mathbf{N}^{\mathbf{0}}$ de empreendimentos \\
\hline Necessidade de complementação de renda & 10 \\
Necessidade de complementação de renda e tradição familiar & 8 \\
Incentivo de instituições locais (Sindicato, Emater, Prefeitura) & 2 \\
Tradição Familiar & 1 \\
\hline
\end{tabular}


Total

21

Fonte: Dados da pesquisa de campo.

Os produtores que elencaram a tradição familiar como uns dos fatores importantes para atuar no segmento agroalimentar mencionam ainda que cresceram acompanhando os pais cultivando e transformando alimentos, principalmente para a subsistência. Desta forma, escolheram utilizar destes conhecimentos para realizar a agregação de renda à produção como uma estratégia para permanecerem nos estabelecimentos agrícolas.

Além disso, outros aspectos importantes emergem da implantação destas atividades. Na visão dos entrevistados, a produção de autoconsumo é fundamental tanto na questão da disponibilidade como na da qualidade dos alimentos. Tal estratégia lhes permite economizarem, representando assim uma vantagem em termos econômicos. Já a qualidade dos produtos está relacionada com a questão da segurança alimentar, uma vez que as famílias podem optar pela produção de base ecológica, com menos utilização de agroquímicos. A diversificação da produção contribui para a redução dos riscos climáticos e de mercado, na medida em que pode proporcionar a minimização das perdas por meio da obtenção de receitas com outros produtos.

A comercialização dos produtos de empreendimentos considerados na pesquisa é transacionada principalmente em feiras do produtor, venda direta em domicílios, venda direta no estabelecimento, e em supermercados locais. Neste sentido os associados da COOPERAC e do SINTRAF comercializam em um espaço disponibilizado pelo SINTRAF no centro urbano. No caso da comercialização nos supermercados, a quantidade varia de acordo com a capacidade de demanda destes empreendimentos, de modo que eles têm o compromisso de abastecê-los em média de duas a três vezes por semana. Algumas agroindústrias comercializam seus produtos no próprio espaço de produção devido à proximidade com o perímetro urbano.

Destaca-se que dos 21 empreendimentos estudados, 13 são certificados pelo SIM. Porém, o SIM restringe a comercialização de produtos de origem animal, no caso as agroindústrias de embutidos de carne suína e as de derivados de leite, à possibilidade de comercializarem somente dentro do município (PREZOTTO, 2013). No entanto, nove dos empreendimentos que possuem o SIM são associados da COOPERAC. Os associados da cooperativa utilizam os selos de certificação Sabor Gaúcho ${ }^{5}$, que concede às agroindústrias, principalmente, o direito de comercialização em feiras dentro do estado do Rio Grande do Sul, o que amplia geograficamente o mercado. Já o selo

\footnotetext{
${ }^{5} \mathrm{O}$ selo Sabor Gaúcho é uma marca que identifica os produtos provenientes da agricultura familiar gaúcha. O selo é destinado aos participantes do Programa Estadual de Agroindústria Familiar (PEAF).
} 
Vita Colônia foi criado pela cooperativa como uma marca para diferenciar o produto de origem colonial no mercado (Quadro 3). Os agricultores apontaram que, por meio da COOPERAC, conseguiram comercializar seus produtos nas feiras estaduais e em eventos regionais. Por intermédio de projetos da cooperativa, acessaram recursos do governo federal para a aquisição de caminhão, caminhonetes e equipamentos. Desta forma, destaca-se o papel das instituições na facilitação e/ou viabilização de inserção em mercados tanto locais como ampliados para produtos da agricultura familiar.

Conforme o Quadro 3, as agroindústrias que mais dependem de matéria-prima de origem externa são as de embutidos de carne suína e as de derivados de leite. No caso do abastecimento das agroindústrias de embutidos de suínos, a matéria prima advém principalmente de granjas habilitadas do município. Já no caso das de derivados de leite, elas são abastecidas por produtores de leite locais, próximos das agroindústrias. A matéria-prima para as agroindústrias de panificados são oriundas dos supermercados locais e da agricultura familiar. Já no caso dos insumos dos produtores de hortifrutigranjeiros, as sementes e mudas são provenientes do viveiro de mudas municipal, e o adubo, dos aviários locais. É importante ressaltar que somente 5 dos 21 estabelecimentos estudados são autossuficientes e produzem sua matéria-prima. Ao mesmo tempo em que esse fator, por um lado, os torna dependentes de insumos externos à atividade, por outro, ele dinamiza outros estabelecimentos no entorno.

\section{Quadro 3 - Origem/fonte dos fatores de produção e comercialização dos empreendimentos}

\begin{tabular}{|c|c|c|c|}
\hline Agroindústria & Utilização de Selos & Origem da mão de obra & $\begin{array}{c}\text { Origem da } \\
\text { matéria-prima }\end{array}$ \\
\hline A1 & $\begin{array}{c}\text { SIM, Sabor Gaúcho e Vita } \\
\text { Colônia }\end{array}$ & Totalmente Familiar & Totalmente comprada \\
\hline A2 & Não Possui & Totalmente Familiar & Totalmente comprada \\
\hline A3 & $\begin{array}{c}\text { SIM, Sabor Gaúcho e Vita } \\
\text { Colônia }\end{array}$ & Totalmente Familiar & Totalmente comprada \\
\hline A4 & Não Possui & Totalmente Familiar & Totalmente comprada \\
\hline A5 & $\begin{array}{c}\text { SIM, Sabor Gaúcho e Vita } \\
\text { Colônia }\end{array}$ & Totalmente Familiar & Totalmente comprada \\
\hline A6 & SIM, Sabor Gaúcho e Vita & $\begin{array}{c}\text { Parcialmente familiar e } \\
\text { contratada temporária }\end{array}$ & Totalmente comprada \\
\hline A7 & $\begin{array}{c}\text { SIM, Sabor Gaúcho e Vita } \\
\text { Colônia }\end{array}$ & Totalmente Familiar & Totalmente produzida no EA \\
\hline A8 & $\begin{array}{c}\text { SIM, Sabor Gaúcho e Vita } \\
\text { Colônia }\end{array}$ & Totalmente Familiar & Totalmente produzida no EA \\
\hline A9 & SIM, Sabor Gaúcho e Vita \\
Colônia & Totalmente Familiar & Totalmente produzida no EA \\
\hline A10 & $\begin{array}{c}\text { SIM, Sabor Gaúcho e Vita } \\
\text { Colônia }\end{array}$ & $\begin{array}{c}\text { Parcialmente familiar e } \\
\text { contratada temporária }\end{array}$ & Totalmente produzida EA \\
\hline
\end{tabular}




\begin{tabular}{|c|c|c|c|}
\hline A11 & $\begin{array}{c}\text { SIM, Sabor Gaúcho e Vita } \\
\text { Colônia }\end{array}$ & $\begin{array}{c}\text { Parcialmente familiar e } \\
\text { contratada temporária }\end{array}$ & 70 a $80 \%$ comprada \\
\hline P12 & SIM & $\begin{array}{c}\text { Parcialmente familiar e } \\
\text { contratada permanente }\end{array}$ & 80 a $90 \%$ comprada \\
\hline P13 & SIM & Totalmente Familiar & Totalmente comprada \\
\hline P14 & SIM & $\begin{array}{c}\text { Parcialmente familiar e } \\
\text { contratada temporária }\end{array}$ & Totalmente comprada \\
\hline P15 & Não Possui & $\begin{array}{c}\text { Parcialmente familiar e } \\
\text { contratada temporária }\end{array}$ & 80 a 90\% comprada \\
\hline H16 & Não Possui & Totalmente Familiar & Totalmente comprada \\
\hline H17 & Não Possui & Totalmente Familiar & Totalmente produzida no EA \\
\hline H18 & Não Possui & Totalmente Familiar & 10 a 20\% comprada \\
\hline H19 & Não Possui & Totalmente Familiar & Totalmente comprada \\
\hline H20 & Não Possui & Totalmente Familiar & Totalmente comprada \\
\hline H21 & &
\end{tabular}

Fonte: Dados da pesquisa de campo (2017)

EA - Estabelecimento agrícola

A mão de obra utilizada nesses empreendimentos é principalmente a familiar. Em seis agroindústrias observa-se a mão de obra contratada para o auxílio nas atividades. O perfil dos produtores estudados caracteriza-se, em larga medida, pelo meio em que estão inseridos, ou seja, a agricultura familiar (Quadro 3). Assim, verificam-se aqueles que sempre residiram no meio rural, e alguns que tiveram experiências em segmentos urbanos e retornaram ao meio rural motivados pelas melhoras das condições de vida no rural, possibilidade efetiva de sucessão e obtenção de renda das atividades agroindustriais.

Em linhas gerais, o perfil dos produtores estudados demonstra o papel da mão de obra familiar no desenvolvimento das atividades. Também se observa que a comercialização e a implantação da agroindustrialização e/ou dos hortifrutigranjeiros contribuem no sentido de aumentar o portfólio de atividades, ou seja, promovem a diversificação como uma estratégia de redução de risco, seja climático, seja de mercado. Por fim, a comercialização se dá no âmbito local, em que a relação de confiança é determinante no desempenho das atividades, uma vez que essas agroindústrias carregam traços muito fortes daquilo que Marsden (1999) denomina de cadeias agroalimentares curtas.

Quanto à origem do capital para implantação dos empreendimentos, sete deram-se a partir de capital próprio. Os demais, juntamente com o capital próprio, obtiveram financiamentos em bancos e cooperativas de crédito. Houve ainda uma agroindústria que obteve acesso a programas governamentais a fundo perdido. Neste contexto de inserção social e econômica, tornou-se 
importante a presença dos incentivos e programas desenvolvimentistas para a melhor concepção das agroindústrias familiares rurais.

\section{Percepção dos entrevistados referente a características dos produtos e da comercialização}

A percepção, em larga medida, é decorrente de uma leitura que os indivíduos fazem em um determinado espaço de tempo, que condiciona e é condicionada pelas condições objetivas e subjetivas que envolvem, neste caso dos empreendimentos rurais, aspectos produtivos, socioeconômicos, culturais e ambientais.

Ainda que a produção de hortifrutigranjeiros e de processamento de produtos tenha sido implementada em uma perspectiva de diversificação produtiva e de complemento de renda, de acordo com os entrevistados, nos últimos cinco anos foi possível auferir um desempenho financeiro positivo, principalmente no que se refere aos dividendos provenientes da produção de alimentos. Nesta perspectiva, na tabela 4, estão apresentados os principais aspectos que, na visão dos responsáveis pelos empreendimentos, influenciam na comercialização dos produtos.

Tabela 4 - Fatores que influenciam no processo de comercialização, na percepção dos entrevistados

\begin{tabular}{|c|c|c|c|c|c|}
\hline \multirow{2}{*}{ Variável } & $\begin{array}{c}\text { Discordo } \\
\text { Totalmente }\end{array}$ & $\begin{array}{c}\text { Discordo } \\
\text { Parcialmente }\end{array}$ & $\begin{array}{c}\text { Não concordo/Não } \\
\text { discordo }\end{array}$ & $\begin{array}{c}\text { Concordo } \\
\text { Parcialmente }\end{array}$ & $\begin{array}{c}\text { Concordo } \\
\text { Totalmente }\end{array}$ \\
\cline { 2 - 6 } & $\mathbf{( \% )}$ & $\mathbf{( \% )}$ & $\mathbf{( \% )}$ & $\mathbf{( \% )}$ & $\mathbf{( \% )}$ \\
\hline Aparência dos produtos & 0,00 & 0,00 & 4,76 & 14,29 & 80,95 \\
\hline Preço dos produtos & 0,00 & 0,00 & 9,52 & 33,33 & 57,14 \\
\hline Venda porta a porta & 0,00 & 9,52 & 9,52 & 19,05 & 61,90 \\
\hline Relação de confiança & 0,00 & 0,00 & 9,52 & 23,81 & 66,67 \\
\hline Relação de reciprocidade & 0,00 & 9,52 & 0,00 & 23,81 & 66,67 \\
\hline Qualidade dos produtos & 0,00 & 0,00 & 4,76 & 9,52 & 85,71 \\
\hline Origem da matéria-prima & 0,00 & 4,76 & 14,29 & 19,05 & 61,90 \\
\hline Local de comercialização & 4,76 & 14,29 & 0,00 & 23,81 & 57,14 \\
\hline Rotulagem & 14,29 & 23,81 & 14,29 & 28,57 & 19,05 \\
\hline Tabela nutricional & 33,33 & 14,29 & 19,05 & 28,57 & 4,76 \\
\hline
\end{tabular}

Fonte: Dados da pesquisa (2017).

Eles acreditam que são fundamentais as relações interpessoais que dão confiabilidade aos produtos e processos de comercialização, como é o caso dos hortifrutigranjeiros, por exemplo, que são comercializados em um sistema "porta a porta", sem a presença de selos e/ou a formalização do empreendimento. Assim, os entrevistados mencionam que a relação de confiança e de reciprocidade é fundamental para estabelecer a conexão entre produtor-consumidor. Quanto aos produtos, eles 
acreditam que os consumidores valorizam a aparência, os preços e a qualidade no processo de comercialização.

De acordo com os entrevistados, nestes últimos anos, notou-se a maior valorização destas atividades, pois os consumidores, que majoritariamente residem nos centros urbanos, passaram a valorizar de maneira mais efetiva os alimentos, assim como os produtores rurais. Fatores como a importância de saber a procedência dos alimentos consumidos, por exemplo, têm contribuído para aumentar a demanda, bem como valorizar a produção local. Destacam ainda que, por se tratar de um município pequeno, os consumidores consideram a confiança, de modo que a maioria dos clientes se torna fiel, e as transações são recorrentes. Neste contexto, alguns entrevistados mencionam que possuem clientes há vários anos.

Este aspecto está descrito na literatura. Cruz (2012) aborda que as relações de confiança são promovidas por diferentes fatores, como, por exemplo, cuidado no manejo, produção saudável e cuidados com a sustentabilidade ambiental, os quais evidenciam a segurança e o valor nutricional. Assim, as ferramentas para a construção da confiança são as relações de proximidade que, nutridas por aspectos sustentáveis e sanitários, desenvolvem em sequência relações mercantis. Reitera a autora que, neste mercado alternativo de comercialização, os alimentos começaram a ganhar prestígio com a virada da qualidade ${ }^{6}$.

Quanto às questões referentes às tabelas nutricionais, rotulagem e código de barras, os entrevistados entendem que estes aspectos, embora importantes, não estão entre os principais aspectos que influenciam os preços e a demanda do consumidor, principalmente o local. A possibilidade de comprar nos empreendimentos e as relações de proximidade tendem a conferir um valor de qualidade que dispensa a necessidade dos selos e certificações, embora eles sejam de extrema importância, sobretudo em produtos de maior perecibilidade. Esta observação deve-se à proximidade existente entre as partes, pois como se trata de um mercado local, os consumidores possuem a preferência por produtos frescos, o que tende a conferir uma qualidade aos alimentos, sobretudo em produtos in natura, como é o caso dos hortifrutigranjeiros (MARSDEN; SONINNO, 2006).

6 O termo "virada da qualidade" foi cunhado por David Goodman (2003). Evidencia a emergência dos sistemas agroalimentares alternativos, em que o produtor e o consumidor estabelecem relações qualidade e confiança dos alimentos. 
Deste modo, os produtores ainda afirmam que possuem uma demanda crescente de produtos in natura e minimamente processados, de maneira que os consumidores não levam em consideração estes aspectos de rotulação (Tabela 4).

Os entrevistados demostraram-se, em sua maioria, satisfeitos com a relação que possuem com seus clientes. De um modo geral, sobressaiu a vontade dos produtores em continuarem investindo nas agroindústrias, pois acreditam que no futuro terão uma maior lucratividade com a produção de alimentos devido aos consumidores valorizarem cada vez mais aspectos como origem, confiança e reciprocidade.

Neste intuito, nos últimos anos tem havido uma série de programas visando incentivar e fortalecer este segmento. Para a FAO (Organização das Nações Unidas para Alimentação e Agricultura), a agricultura familiar é um setor de produção de alimentos que envolve aspectos socioeconômicos, ambientais e culturais. As políticas públicas para este setor estão fazendo parte das demandas dos movimentos sociais em prol do desenvolvimento e de um maior apoio ao setor rural (FAO, 2016).

No entanto, existe uma série de desafios que os empreendedores encontram, principalmente no que diz respeito à expectativa da ampliação da produção e consequentemente nos mercados no longo prazo. Se de um lado existe a expectativa da ampliação da demanda, por outro, a expansão dos empreendimentos tem esbarrado na dificuldade de realizar a sucessão familiar, situação enfrentada por aproximadamente $90 \%$ dos entrevistados, visto que os mais jovens têm preferência por migrarem para outros segmentos, principalmente no urbano.

\section{CONSIDERAÇÕES FINAIS}

Pesquisadores internacionais e nacionais vêm destacando a importância socioeconômica dos empreendimentos que produzem, transformam e comercializam alimentos, vinculados a estabelecimentos rurais familiares. Estes desempenham um papel importante no que concerne à oferta de alimentos para a população, na ocupação e na geração de renda das famílias que atuam nesse segmento, na diversificação das atividades e na reciprocidade com os consumidores.

Partindo do pressuposto de que estes estabelecimentos rurais têm papel ativo no desenvolvimento rural, buscou-se, neste trabalho, identificar o perfil e a percepção acerca das atividades dos agentes responsáveis pelas agroindústrias familiares rurais.

Em termos de atividades, tanto a comercialização de hortifrutigranjeiros como a agroindustrialização são apontadas como atividades complementares, mas que têm uma função 
estratégica em decorrência da otimização da mão de obra familiar disponível, da diversificação e agregação de renda, e da redução dos riscos climáticos e de mercado. Assim, em uma perspectiva mais ampla, é relatada pelos entrevistados uma melhoria na qualidade de vida e nas condições financeiras das famílias.

No entanto, é importante salientar que, apesar das dificuldades, os empreendedores vislumbram a expansão da atividade, uma vez que esse tipo de produto, associado à tradição e aos mercados locais, tem sido mais valorizado, dada a relação com a segurança alimentar. Por isso, estas formas alternativas de produção e transformação encontram na agricultura familiar, por exemplo, um ambiente favorável para o seu desenvolvimento. Com isso, a agricultura familiar no Brasil, que desde o período da modernização tem sido pouco valorizada e, não raro, excluída de políticas públicas e projetos de desenvolvimento, tem tido a oportunidade de se reorganizar e se reafirmar como um segmento importante para o desenvolvimento rural.

Neste sentido, os resultados da pesquisa contribuem para endossar um conjunto de outras pesquisas já existentes que demonstram a importância da produção local na oferta de alimentos de qualidade e na agregação de valor aos produtos, contribuindo para a geração de renda e para a qualidade de vida no campo e nas cidades, e por consequência, no desenvolvimento regional.

\section{REFERÊNCIAS}

AGNE, C. L.; WAQUIL, P. D. A rede de relações sociais nos mercados de proximidade: os canais de comercialização e troca das agroindústrias rurais familiares da região do COREDE Jacuí centro - RS. Revista Ensaios. Porto Alegre, v. 31, p. 779-806, jun. 2011. Disponível em: http://revistas.fee.tche.br/index.php/ensaios/article/view/2579. Acesso em: 29 jun. 2020.

BOURSCHEID, A. et al. As qualidades das agroindústrias rurais familiares gaúchas. In: ENCONTRO DE ECONOMIA GAÚCHA, 8. 2016, Porto Alegre. Anais... EEG: Porto Alegre, 2016. Disponível em: http://www.pucrs.br/face/wpcontent/uploads/sites/6/2016/03/10_ANDR\%C3\%ABIA-BOURSCHEID.pdf. Acesso em: 28 ago. 2020 .

CARON, P. Sistemas alimentares para o desenvolvimento sustentável: propostas para uma profunda transformação em quatro partes. PREISS, P.V.; SCHNEIDER, S. (Org.). Sistemas alimentares no século 21: debates contemporâneos. 1ed. Porto Alegre: Editora da UFRGS, 2020. p. 25-50. Disponível em: https://lume.ufrgs.br/handle/10183/211399. Acesso em: 28 ago. 2020.

CASSOL, A. P. Redes Agroalimentares Alternativas: Mercados, Interação Social e a Construção da Confiança, 2013. (Dissertação de Mestrado em Sociologia). Universidade Federal do Rio Grande do Sul, Porto Alegre, Brasil. Disponível em:

https://lume.ufrgs.br/handle/10183/79442. Acesso em: 08 jun. 2020. 
CONTERATO, M.A.; VASCONCELLOS, F.F. Políticas públicas e consumo sustentável. PREISS, P.V.; SCHNEIDER, S. (Org.). Sistemas alimentares no século 21: debates contemporâneos. 1ed. Porto Alegre: Editora da UFRGS, 2020. p. 177-198. Disponível em: https://lume.ufrgs.br/handle/10183/211399. Acesso em: 28 ago. 2020.

CRUZ, F. T. Produtores, consumidores e valorização de produtos tradicionais: um estudo sobre qualidade de alimentos a partir do caso do queijo serrano dos Campos de Cima da Serra RS, 2012. (Tese de doutorado em Desenvolvimento Rural), Universidade Federal do Rio Grande do Sul, Porto Alegre, Brasil. 2012. Disponível em:

https://www.lume.ufrgs.br/handle/10183/61937. Acesso em 22 jun. 2020.

CRUZ, F. T. Qualidade e boas práticas de fabricação em um contexto de agroindústrias rurais de pequeno porte. Dissertação (Mestrado em Agroecossistemas) - Universidade Federal de Santa Catarina, Centro de Ciências Agrárias. Programa de Pós-Graduação em Agroecossistemas, Florianópolis: UFSC, 2007.

CRUZ, F. T.; MATTE, A.; SCHNEIDER, S. (Org.). Produção, consumo e abastecimento de alimentos: desafios e novas estratégias. Porto Alegre: Editora da UFRGS, Série Estudos Rurais, 2016, 324 p.

CRUZ, F. T.; MENASCHE, R. Tradition and diversity jeo pardised by foods afety regulations? The Serrano Cheesecase, Campos de Cima da Serra region, Brazil. Food Policy, v. 45, p. 116-124, 2014.

CRUZ, F.T. Agricultura familiar, processamento de alimentos e avanços e retrocessos na regulamentação de alimentos tradicionais e artesanais. Revista de Economia e Sociologia Rural, v. 58, p. 1-21, 2020.

ELLIS, F. Rural livelihoods and diversity in developing countries. Oxford: Oxford University Press, 2000.

FAO. Organização das Nações Unidas Para a Alimentação e Agricultura. Superação da Fome e da Pobreza rural: Iniciativas Brasileiras. Brasília, 2016. Disponível em: http://www.fao.org/3/ai5335o.pdf. Acesso em: 17 jul. 2020.

FERNANDES, D. M. M.; ENGEL, B. S. agroindústrias familiares rurais: vantagens e desvantagens da legalização. Redes (St. Cruz Sul, Online), v. 21, n. 3, p. 183-214, set./dez. 2016.

FORNAZIER A, BELIK W. Produção e consumo local de alimentos: novas abordagens e perspectivas para as políticas públicas. Segur. Aliment. Nutr. v. 20, n. 2, p. 204-18. 2013.

GARCIA-PARPET, M. Valorização dos produtos locais e mundialização dos mercados. In: MARQUES, F. C.; CONTERATO, M. A.; SCHNEIDER, S. Construção de Mercados e Agricultura Familiar: desafios para o desenvolvimento rural. Porto Alegre: Editora da UFRGS, 2016. p. 159-182.

GAZOLLA, M. Por que muitos agricultores não formalizam o comércio de alimentos através das cadeias curtas?. In: GAZOLLA, M.; SCHNEIDER, S. (Org.). Cadeias curtas e redes agroalimentares alternativas. Porto Alegre: Editora da UFRGS, 2017. p. 455-472.

GAZOLLA, M.; PELEGRINI, G. A. Agroindustrialização como estratégia de reprodução social da agricultura familiar. Estud. Soc. e Agric. Rio de Janeiro, v. 2, n. 2, p. 332-378, 2008. Disponível em:http://socialsciences.scielo.org/pdf/s_esaa/v4nse/scs_a09.pdf. Acesso em: 08 jul. 2020. 
GOODMAN, D. The Quality 'Turn' and Alternative Food Practices: Reflections and Agenda. Journal of Rural Studies, v. 19, p. 1-7, 2003. DOI: 10.1016/S0743-0167(02)00043-8

GRANOVETTER, M. Ação Econômica e Estrutura Social: o problema de imersão. ERA eletrônica. v. 6, n. 1, artigo 9 jan./jun. 2007. Disponível em: https://rae.fgv.br/rae-eletronica/vol6num1-2007/acao-economica-estrutura-social-problema-imersao. Acesso em: 28 jul. 2020.

HENNIG, C, C. Dinâmica agrária e desenvolvimento local: emergência e efeitos econômicos diretos e indiretos da agroindustrialização familiar de pequeno porte em Constantina - RS, 2010. (Dissertação de mestrado em Desenvolvimento). Universidade Regional do Noroeste do estado do Rio Grande do Sul, Ijuí, Brasil. Disponível em:

http://bibliodigital.unijui.edu.br:8080/xmlui/bitstream/handle/123456789/89/Cristiane\%20De\%20 Conti\%20Hennig.pdf?sequence=1. Acesso em: 24 jul. 2020.

INSTITUTO BRASILEIRO DE GEOGRAFIA E ESTATÍSTICA - IBGE. Censo Agropecuário de 2017. Rio de Janeiro: IBGE, 2019.

INSTITUTO BRASILEIRO DE GEOGRAFIA E ESTATÍSTICA - IBGE. Censo Demográfico, 2010. Cidades. Rio de Janeiro: IBGE, 2010.

INSTITUTO BRASILEIRO DE GEOGRAFIA E ESTATÍSTICA - IBGE. IBGE Cidades de 2017, Panorama do município de Constantina. Brasil. Rio de Janeiro: IBGE, 2017.

MARSDEN, T. Rural Futures: The Consumption Countryside and its Regulation. Sociologia Ruralis, v. 39, n. 4, p. 501-520, 1999.

MARSDEN, T.; SONNINO, R. Beyond the divide: rethinking relationships between alternative and conventional food networks in Europe. Journal of economic geography, v. 6, p. 181-199, 2006.

MIOR, L. C. Agricultores familiares, agroindústrias e redes de desenvolvimento rural. Chapecó: Editora Argos, 2005.

PELEGRINI, G., GAZOLLA, M. Caracterização e análise das agroindústrias familiares da Região do Médio Alto Uruguai (CAAF, 2006). Relatório Final de Pesquisa. Edital FAPERGS 001/2005-PROCOREDES, Frederico Westphalen, 2007. Disponível em: <http://r1.ufrrj.br/esa/V2/ojs/index.php/esa/article/viewFile/316/312>. Acesso em: 28 jul. 2020.

PLOEG, J. D. Camponeses e a arte da agricultura. Porto Alegre: Editora da UFRGS, 2016.

PLOEG, J. D. Trajetórias do desenvolvimento rural: pesquisa comparativa internacional.

Sociologias. Porto Alegre, v. 7, n. 27, p. 114-140. 2011.

PREZOTTO, L. Manual de orientações sobre constituição de Serviço de Inspeção Municipal (SIM). Brasília, 2013. Disponível em:

https://www2.mppa.mp.br/sistemas/gcsubsites/upload/37/MANUAL\%20-\%20SIM\%20-

$\% 20$ Servico\%20de\%20Inspecao\%20Municipal.pdf. Acesso em: 17 jul. 2020.

RAUPP, A.K.; GAZOLLA, M. Programa de agroindústria familiar do Rio Grande do Sul: histórico e alguns resultados na perspectiva da construção de cadeias agroalimentares curtas. In: GAZOLLA, M.; SCHNEIDER, S. (Org.). Cadeias curtas e redes agroalimentares alternativas. Porto Alegre: Editora da UFRGS, 2017. p. 473-490.

SCARABELOT, M.; SCHNEIDER, S. As cadeias agroalimentares curtas e desenvolvimento local: um estudo de caso no município de Nova Veneza/SC. Faz Ciência, v. 15, n. 20, p. 101-130, 2012. 
VIANA, C.E.; TRICHES, R.M.; CRUZ, F.T. Que qualidades para quais mercados? O caso do queijo colonial da microrregião de Capanema, Paraná. Revista NERA, Presidente Prudente, v. 22, n. 29, p. 189-210, mai./ago. 2019.

WAQUIL, P. D. O Perfil da Agroindústria Rural no Brasil: Uma análise com base nos dados do Censo Agropecuário 2006. Porto Alegre: IPEA/PGDR, 2013.

WESZ JUNIOR, V.J. Políticas públicas de agregação de valor e as cadeias curtas: um olhar sobre o Pronaf-Agroindústria. In: GAZOLLA, M.; SCHNEIDER, S. (Org.). Cadeias curtas e redes agroalimentares alternativas. Porto Alegre: Editora da UFRGS, 2017. p. 491-508.

WILKINSON, J. Mercados, redes e valores: o novo mundo da agricultura familiar. Porto Alegre: UFRGS, 2008.

WILKINSON, J.; DORIGON, C.; MIOR, L. C. The emergence of SME agro-industry networks in the shadow of agribusiness contract farming: a case study from the south of Brazil. In:

SILVA, C. A. da; MHLANGA, N. Innovative Policies and Institutions Support Agro-Industries Development. Roma: FAO, p. 87-119, 2011.

WILKINSON, J. Os mercados não vem mais do "Mercado". In MARQUES, F. C.; CONTERATO, M. A.; SCHNEIDER, S. (Eds.), Construção de mercados e agricultura familiar: Desafios para o desenvolvimento rural. Porto Alegre: Editora da UFRGS. 2016. 